\title{
Next-generation sequencing of Dreissena polymorpha transcriptome sheds light on its mitochondrial DNA
}

\author{
Marianna Soroka - Anna Rymaszewska - Tomasz Sańko • \\ Aleksandra Przyłucka • Marek Lubośny • Beata Śmietanka • \\ Artur Burzyński
}

Received: 7 July 2016/Revised: 16 November 2016/ Accepted: 3 January 2017/Published online: 13 January 2017

(C) The Author(s) 2017. This article is published with open access at Springerlink.com

\begin{abstract}
Zebra mussels Dreissena polymorpha (Veneroida, Dreissenidae) are known for their invasive behavior. Despite numerous studies dealing with this species, no results of large sequencing projects have been published to date, hampering marker development. In this study, we present a relatively large novel transcriptomic dataset obtained by Illumina MiSeq technology from mantle and male gonad of D. polymorpha sampled in Poland. The transcriptomic data were typical for the tissue analyzed. Moreover, they showed the expression of a single
\end{abstract}

Guest editors: Manuel P. M. Lopes-Lima, Ronaldo G. Sousa, Lyuba E. Burlakova, Alexander Y. Karatayev \& Knut Mehler / Ecology and Conservation of Freshwater Bivalves

Electronic supplementary material The online version of this article (doi:10.1007/s10750-017-3088-4) contains supplementary material, which is available to authorized users.

M. Soroka $(\bowtie) \cdot$ A. Rymaszewska

Department of Genetics, Faculty of Biology, University of Szczecin, Felczaka 3c, 71-412 Szczecin, Poland

e-mail: soroka.marianna@gmail.com
A. Przyłucka · M. Lubośny · B. Śmietanka ·
A. Burzyński
Institute of Oceanology, Polish Academy of Sciences,
Powstańców Warszawy 55, 81-712 Sopot, Poland

T. Sańko

Faculty of Natural Sciences, Environmental Sciences and Management: Microbiology, North-West University,

Potchefstroom, South Africa mitochondrial genome, indicating that this species do not have doubly uniparental inheritance of mitochondria. The sequences of mitochondrial transcripts were used to design primers and obtain nearly complete sequence of the zebra mussel mitochondrial genome by PCR and Sanger sequencing. This mitogenome has unique gene order, with the genes split into two blocks encoded in opposite directions. The closest mitogenome available in GenBank belongs to the marine clam Mya arenaria (Myoida, Myidae). The average divergence of the sequences of these mitogenomes is quite high, in the range of $20 \%$. Both mitogenomic and transcriptomic resources should prove very useful for elucidating population genetics and conservation issues involving this important species.

Keywords Zebra mussel - Invasive species · Mitochondrial genome $\cdot$ Genetic mapping $\cdot$ NGS

\section{Introduction}

The freshwater zebra mussel, Dreissena polymorpha (Pallas, 1771) (Dreissenidae), is one of the most successful invaders in terms of abundance and high density (Nalepa \& Schlosser, 1993; Van der Velde et al., 2010; Schlosser \& Schmuckal, 2012; Sousa et al., 2014). Native to the lakes, slow moving rivers and low salinity areas of the Black, Caspian and Azov Seas regions of central and eastern Europe, the zebra 
mussel was introduced to northwestern Russia, much of mainland Europe and England by at least the mid1800 s by the construction of canal systems in Europe and Russia that linked several major river drainages. The zebra mussel together with the quagga mussel (Dreissena bugensis, Andrusov, 1897) was introduced into the Great Lakes of North America in the mid1980s by the discharge of ballast water from transAtlantic freighters (Stańczykowska, 1977; Hebert et al., 1989; Roberts, 1990; Bij de Vaate et al., 2002; Astanei et al., 2005; Bidwell, 2010). The colonization success of the zebra mussel is largely related to its method of reproduction external mode of fertilization, presence of free-swimming planktonic veliger larval stage, and attachment of juveniles and adults to hard surfaces via byssal threads (Borcherding, 1991; Johnson \& Carlton, 1996). Despite this, there are only relatively few genetic studies of this invader (Stepien et al., 2002; Soroka, 1999, 2002, 2003, 2010; Astanei et al., 2005; Astanei \& Gosling, 2010).

The zebra mussels started expanding their range in Poland approx. 200 years ago, and this expansion was correlated with the development of inland sailing (Stańczykowska, 1977; Bidwell, 2010). It is presumed to have arrived on the Baltic coast via River Nemunas which, at the end of the 18th century, was linked with River Dnieper via the Oginskij Canal (Nowak, 1974; Bidwell, 2010; Kołodziejczyk et al., 2011). In Poland, the earliest record of zebra mussel date from 1824 , from the former Eastern Prussia, whereas it is currently present mainly in Pomeranian, Masurian and Suwalskie Lake District as well as in lagoons, lower stretches, and estuaries of the Vistula and Odra rivers (Stańczykowska, 1977; Lewandowski, 1991; Bidwell, 2010; Stańczykowska et al., 2010).

D. polymorpha is one of the most studied invasive species (Karatayev et al., 1997, 2007; Kołodziejczyk et al., 2011; Schlosser \& Schmuckal, 2012; Sousa et al., 2014); however, most studies concentrate on their ecology, toxicology, and physiology, whereas purely genetic studies are less abundant and concentrate more on North American than European samples (Sousa et al., 2014). Few markers are available, mainly allozyme electrophoretic and RAPDs markers (Hebert et al., 1989; May \& Marsden, 1992; Spidle et al., 1994; Marsden et al., 1995; Lewis et al., 2000; Elderkin et al., 2001, 2004; Stepien et al., 2002). The usefulness of coxl appeared to be limited for the regional and fine-scale European D. polymorpha populations due to very low levels of polymorphism: only 5 haplotypes were observed over 338 individuals by Tarnowska et al. (2013) in France. Generally, the polymorphism measured with these low-resolution and/or anonymous markers led neither to the full understanding of the invasion nor to its better control (Marsden et al., 1995, 1996; Elderkin et al., 2001, 2004; Müller et al., 2002; Stepien et al., 2002).

Several studies used mitochondrial markers to assess genetic polymorphism and connectivity of $D$. polymorpha populations. The only available markers are based on the most conservative coxl and lrn genes. Nevertheless, it has been shown that populations closest to the native range have marginally higher polymorphism in mitochondrial genomes, and a common haplotype is present in all sampled locations in Europe and North America, with the overall diversity derived from cox 1 sequencing not exceeding 1.1\% (Baldwin et al., 1996; Giribet \& Wheeler, 2002; Therriault et al., 2004; Albrecht et al., 2007; Soroka, 2010).

We maintain that the available genetic resources, including the mitochondrial variation currently recognized, are inadequate to fully characterize the $D$. polymorpha range expansion in Europe. Consequently, we will present here an attempt to fill the gap by providing a large amount of original transcriptomic data and a nearly complete mitogenome of $D$. polymorpha.

\section{Materials and methods}

A sample of 10 zebra mussels was collected from lake Wdzydze $\left(54^{\circ} 01^{\prime} 34.21^{\prime \prime} \mathrm{N}, 17^{\circ} 55^{\prime} 31.96^{\prime \prime} \mathrm{E}\right)$ in July 2010. Fresh animals were transported to the laboratory, sexed by microscopic examination of gonadal tissues. Both RNA and DNA were extracted from mantle/gonadal tissue of the same male individual using established protocols (Sańko \& Burzyński, 2014). The total RNA sample was sent to Macrogen (South Korea). Library preparation and next-generation sequencing (NGS) was performed by Macrogen, using TrueSeq kit and MiSeq $2 \times 150$ bp technology. Approximately $3.5 \times 10^{6}$ raw sequence reads were obtained. They were preprocessed and assembled using CLC Genomics workbench software v. 9.01 (QIAGENE), under default settings for de novo NGS assembly. The assembly was evaluated by TransRate 
(Smith-Unna et al., 2016) and BUSCO (Simão et al., 2015) applications. TransRate is a tool for referencefree quality assessment of de novo transcriptome assemblies, using only the sequenced reads and the assembly as input. BUSCO (Benchmarking Universal Single-Copy Orthologs) is a measure for quantitative assessment of genome assembly and annotation completeness based on evolutionarily informed expectations of gene content. The obtained set of transcripts was first analyzed for the presence of mitochondrial transcripts by wise 2 searches (Birney et al., 2004) using hmm profiles of mitochondrialy encoded proteins (Finn et al., 2010) and by nhmmer (Wheeler \& Eddy, 2013) searches using hmm profiles of mitochondrialy encoded ribosomal RNA genes (GriffithsJones, 2003). The sequences of mitochondrial contigs were then used to design specific primers (Supplementary Table S1) for mtDNA amplification and Sanger sequencing. Sequence annotation was achieved by comparative analysis: the original annotations form wise 2 searches were verified with ORFfinding and BLAST (Altschul et al., 1990) searches from within the CLC software. In addition, the trn genes were identified using arwen software (Laslett \& Canbäck, 2008). To better evaluate the structure of mitochondrial transcripts, the quality filtered reads were mapped onto the final annotated mitochondrial contig in CLC software. The remaining contigs were analyzed using the BLAST2GO application (Conesa et al., 2005). Phylogenetic analysis based on transcriptomic data was conducted by adding $D$. polymorpha transcript sequences to the reference alignments downloaded from the DRYAD repository (González et al., 2014) and following similar methodology (González et al., 2015). Maximum-likelihood tree searches were conducted with RAxML v. 8.2.8 (Stamatakis, 2006), using a model of protein evolution with corrections for a discrete gamma distribution with the LG model ("-m PROTGAMMALG" option) (Le \& Gascuel, 2008). Bootstrap resampling was conducted for 100 replicates using a rapid bootstrapping algorithm (Stamatakis et al., 2008), and the support values were mapped onto the optimal tree.

The annotated mitochondrial and assembled transcriptomic sequences as well as raw sequence data have been deposited in GenBank under the following accession numbers: mitogenome-KY091877, raw data-SRR5000302. The Transcriptome Shotgun Assembly project has been deposited at DDBJ/
EMBL/GenBank under the accession GFBQ000 00000. The version described in this study is the first version, GFBQ01000000.

\section{Results}

General transcriptome data

The overall quality of the assembly was good, with a TransRate score at 0.18 and approximately 150 BUSCOs present. Given the general lack of annotated reference data for bivalves, this is a good result. There were 26636 contigs, out of which approx. 7500 were positively identified by Blast2GO application (Supplementary Fig. S1), showing diverse distribution of contigs among various GO terms, typical for bivalvian mantle (Sleight et al., 2016; Vendrami et al., 2016; Yarra et al., 2016).

The transcriptome provided 1136 loci compatible with the general phylogenetic framework proposed by González et al. (2015), out of 1377 loci present in the largest supermatrix of González et al. (2014). These were combined forming the new supermatrix, composed of 276,775 alignment patterns. The overall proportion of missing data in this dataset was $46.2 \%$, very similar to the original one $(46.6 \%)$. This slight decrease was caused by the fact that some of the included transcripts were incomplete, effectively shortening the alignment. This effect was nevertheless negligible. The performed maximum-likelihood analysis of bivalvian phylogeny based on this new dataset was sufficiently informative to unambiguously place D. polymorpha in the general bivalvian phylogenetic context. The obtained tree (Fig. 1) has an overall topology that is identical to the original one (González et al., 2015; Fig. 1) and places D. polymorpha in relatively close proximity to Mya arenaria.

Mitogenome data

It was possible to close all but one gap between the mitochondrial contigs leading to a single, linear contig containing all identified mitochondrial transcripts. The mitochondrial contig was more than 18,450 bp long (Fig. 2). Despite much effort, it was impossible to amplify the fragment spanning the last gap, between $n a d 2$ and nad5 genes. The remaining part of this contig is quite complete: both rRNA genes were 


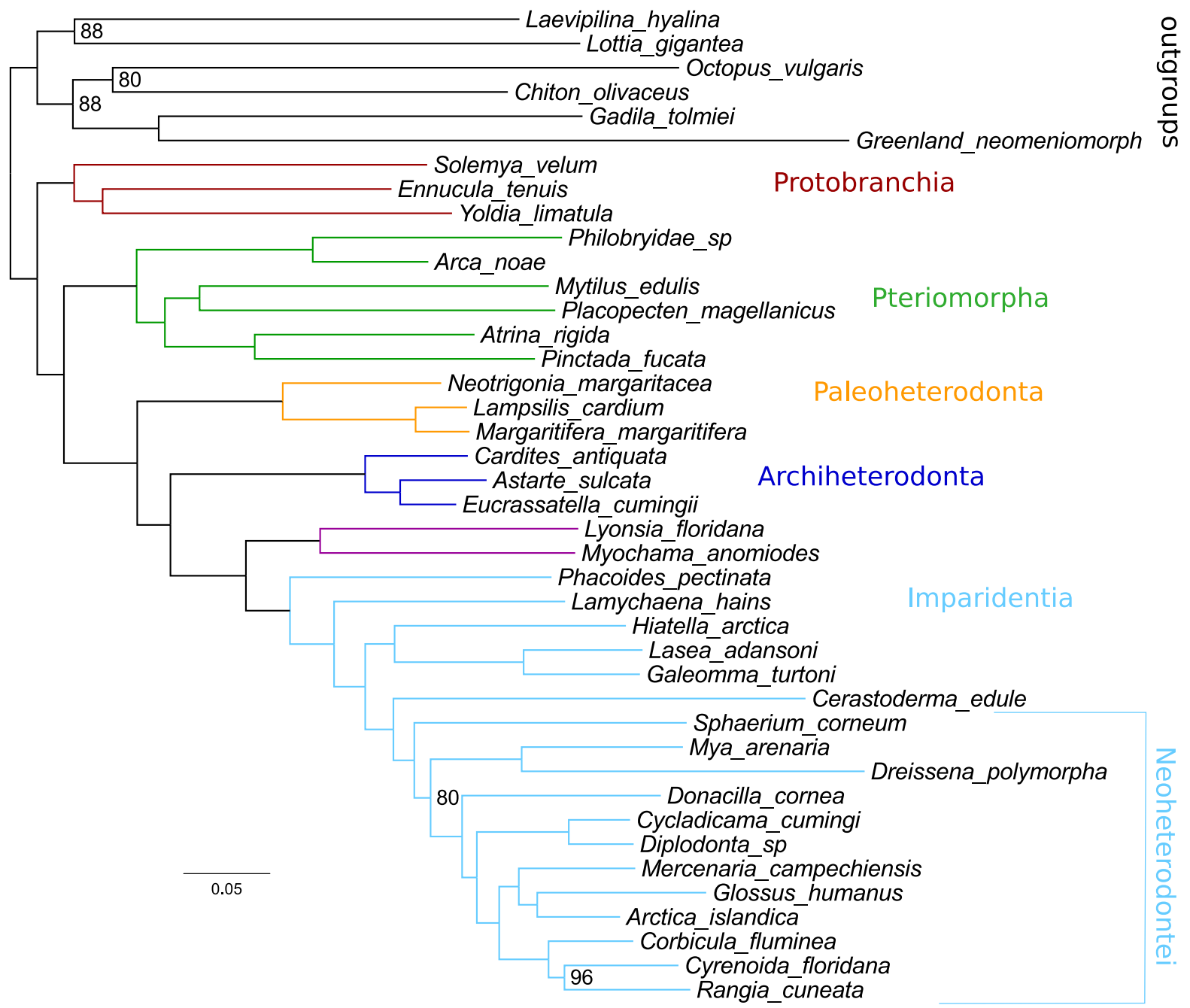

Fig. 1 Phylogenetic tree of Bivalvia reconstructed using ML method, based on concatenated alignment of 1136 amino acid sequences, and total number of alignment patterns was 276,775 . The alignment was obtained by adding homologous $D$. polymorpha sequences to the largest supermatrix of González

identified as well as 12 protein-coding genes (CDS). The only missing CDS was atp8. Several tRNA genes were unequivocally placed on the map forming a reasonably complete annotation. The three exceptions were the missing $\operatorname{trn} L$ and the $\operatorname{trn} C$ genes and the presence of one extra $t r n W$. Transcript mapping of the raw cDNA reads to the assembled mitochondrial contig revealed the pattern of transcripts, with similar and very high sequence coverage for most CDS and much higher coverage for $l r n$. The average coverage for the contig was very high (Table 1), sufficient to positively identify, and map all polyadenylation sites et al. (2014). The colors in the figure follow the convention used by González et al. (2015). Bootstrap support values were $100 \%$ for all nodes, with the exception of the few for which the actual value is shown in the picture

(Fig. 2). Apparently, the genes in this genome are encoded in two blocks of opposite transcriptional orientations. Most transcripts cover just a single gene, with the exception of a nd6-cytb pair which forms a bicistronic transcript. Neither transcripts nor PCR products showed any sequence polymorphism, indicating that only one mitochondrial genome was present and expressed in the analyzed tissues, without even trace evidence for heteroplasmy.

The partial sequences of coxl (KC429149, AF474404, EU484431, EF414494, AM748975, DQ840121, AF510510, JX239087: Marescaux \& 


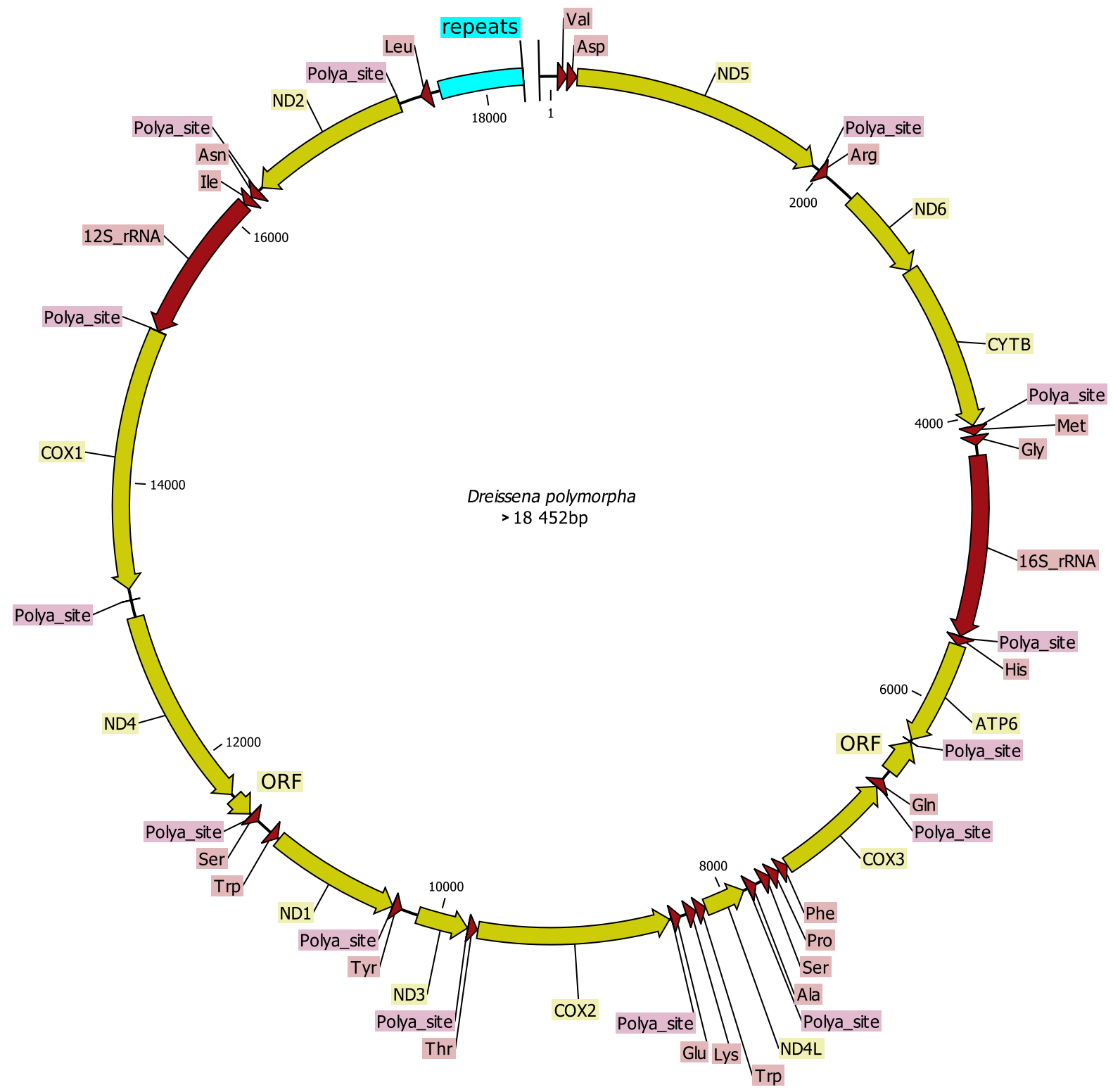

Fig. 2 Gene order of the mitochondrial DNA of Dreissena polymorpha, based on transcriptome and amplicon sequencing and comparative annotations. All CDS, rRNA and tRNA, are

Van Doninck, 2013) and lrn (DQ280038, KP052744, DQ333747: Giribet et al., 2006; Van der Velde et al., 2010) genes of D. polymorpha present in GenBank perfectly match the respective fragment of this genome, confirming its identity. BLAST searches with all annotated $D$. polymorpha mitochondrial genes against RefSeq database pointed at the mitogenome belonging to $M$. arenaria as the closest one. However, the gene order of $D$. polymorpha mitogenome is labeled; three letter amino acid code is used to indicate tRNA specificity. Arrows indicate the direction of transcription

unique, not resembling that of $M$. arenaria and the sequence homology was also relatively weak, at $60 \%$ sequence identity for cox $1,55 \%$ for $c y t b$ and $35 \%$ for atp6.

There were three relatively long unassigned regions in the mitogenome. The largest one contained an array of AT-rich tandem repeats. The length of the repeat unit was 121-133 bp, but the number of repeats was difficult to infer reliably using short-reads NGS. The 
Table 1 Mitochondrial transcript mapping statistics

\begin{tabular}{ll}
\hline Total reference length & 18,452 \\
GC contents in \% & 35.12 \\
Total read count & 948,671 \\
Mean read length & 142.82 \\
Total read length & $135,484,773$ \\
Total reference length & 18,452 \\
Minimum coverage & 0 \\
Maximum coverage & 293,602 \\
Average coverage & $7,326.28$ \\
Standard deviation & $29,628.64$ \\
Minimum excl. zero coverage regions & 1 \\
Average excl. zero coverage regions & $7,531.17$ \\
Standard deviation excl. zero coverage regions & $30,014.39$ \\
\hline
\end{tabular}

assembly suggested the presence of at least 6 repeats. There were also two short open reading frames (ORFs) present within the URs. The shorter one, 153 bp long, was located between $t r n S$ and $n d 4$, while the longer one, 246 bp long, was located between $\operatorname{trn} Q$ and atp6. Neither of the predicted protein sequences encoded by these ORFs had any similarity to known proteins in $B L A S T$ and wise2 searches against $n r$ and pfam databases.

\section{Discussion}

Some bivalve species have an exotic system of mitochondria inheritance called DUI (doubly uniparental inheritance) resulting in male heteroplasmy for two, often very divergent mitogenomes (Skibinski et al., 1994; Zouros et al., 1994). Since DUI has been reported also for a venerid clam Ruditapes philipinarum (Passamonti \& Scali, 2001), it could have been expected in D. polymorpha, too. However, based on the presented data, it can be positively concluded that zebra mussels do not have DUI as their male gonads are homopalsmic, both at the genetic and transcriptomic levels. The representative mitochondrial genome was characterized at unprecedented level by providing its nearly complete sequence. The incompleteness of this mitogenome of is unfortunate. There are several possible reasons for this failure, but the most likely one is the presence of long and complex repeats coupled with the apparently difficulty of melting secondary structures within the missing part of the mitogenome. The alternative hypothesis would be that the mitogenome is actually linear in this species. There are very few examples of linear mitogenomes in animals, most notably atypical structures have been reported in some crustaceans (Doublet et al., 2012). Either way the complete structure could probably be solved only by using modern NGS technique allowing much longer reads. Other than the structural uncertainty, this genome is reasonably complete, with the possible exception of atp8. This is not surprising given the difficulties associated with detection of this gene (Breton et al., 2010; Śmietanka et al., 2010). The possibility that one of the anonymous ORFs is in fact encoding atp8 cannot be dismissed; however, there is also no positive argument supporting such a claim. Similar sequences do not exist even in the closest mitogenome of $M$. arenaria. Ultimately, increasing taxonomic sampling of mitogenomes will allow better comparative analysis and may lead to correct identification of these ORFs. The missing and/ or extra trn genes could well be the consequence of incompleteness or imprecise genome annotations. It can be argued that there are no numts (nuclear mitochondrial DNA segments) contaminating our data because transcript mapping shows typical pattern of expression and numts are generally not expressed. In fact, even taking into account that the overrepresentation of mitochondrial transcript is a typical feature of animal RNA-seq datasets (Smith, 2013), the observed proportion (more than $26 \%$ ) of mitochondrial transcripts was very high. In this context, it is a little surprising that the expression of nad6 was much lower than that of the other genes. This may be due to the bicistronic nature of its transcript and the fact that library construction involves priming of the first strand cDNA synthesis from the oligo-dT-based primer which may contribute to the under-representation of $3^{\prime}$ ends of transcripts in the library. Bicistronic transcripts have been observed previously in other bivalves (Chatzoglou et al., 2013; Sańko \& Burzyński, 2014).

The phylogenetic relationships within Bivalvia are a matter of ongoing debate. The early inferences based on poor molecular markers often conflicted with established views based on morphological characters, up to the point of questioning the monophyly of Bivalvia (Plazzi et al., 2013). Fortunately, these conflicts can usually be resolved by providing more molecular data. For Bivalvia, the recent analysis of 
transcriptomes representing all major lineages is such a keystone (González et al., 2015), solving most conflicts. It is therefore reassuring that the presented transcriptomic dataset is fully compatible with this methodology and supports the placement of Dreissenids in close proximity with Myidae, confirming the recent findings based on a much smaller dataset (Bieler et al., 2014) and in accordance also with the presented mitogenomic data. The only existing NGSderived D. polymorpha dataset was targeted at STR (short tandem repeats, also known as microsatellites) marker development and contains relatively low number of unique contigs (Peñarrubia et al., 2015). Moreover, nearly all microsatellite sequences of $D$. polymorpha deposited in GenBank can be also found in the presented transcriptomic dataset, demonstrating that it can be also a good data source for STR marker development.

The presented set of transcriptomic and mitogenomic data should be beneficial for development of highly variable genetic markers that is needed for studying and managing of $D$. polymorpha invasions.

Acknowledgements This work was partially supported by Polish Ministry of Higher Education Grant no. N 30336433 to MS and Polish National Science Center Grant no. UMO-2012/ 07/B/NZ2/01991 to BS. Computer intensive analyses were run on PLGRID high-performance computer clusters.

Open Access This article is distributed under the terms of the Creative Commons Attribution 4.0 International License (http:// creativecommons.org/licenses/by/4.0/), which permits unrestricted use, distribution, and reproduction in any medium, provided you give appropriate credit to the original author(s) and the source, provide a link to the Creative Commons license, and indicate if changes were made.

\section{References}

Albrecht, C., R. Schultheiß, T. Kevrekidis, B. Streit \& T. Wilke, 2007. Invaders or endemics? Molecular phylogenetics, biogeography and systematics of Dreissena in the Balkans. Freshwater Biology 52: 1525-1536.

Altschul, S. F., W. Gish, W. Miller, E. W. Myers \& D. J. Lipman, 1990. Basic local alignment search tool. Journal of Molecular Biology 215: 403-410.

Astanei, I. \& E. Gosling, 2010. A microgeographic analysis of genetic variation in Dreissena polymorpha in Lough Key, Ireland. In Van der Velde, G., S. Rajagopal \& A. Bij de Vaate (eds), The zebra mussels in Europe. Backhuys Publishers, Leiden/Margraf Publishers, Weikersheim.
Astanei, I., E. Gosling, J. Wilson \& E. Powell, 2005. Genetic variability and phylogeography of the invasive zebra mussel, Dreissena polymorpha (Pallas). Molecular Ecology 14: 1655-1666.

Baldwin, B. S., M. Black, O. Sanjur, R. Gustafson, R. A. Lutz \& R. C. Vrijenhock, 1996. A diagnostic molecular marker for zebra mussels (Dreissena polymorpha) and potentially cooccurring bivalves: mitochondrial COI. Molecular Marine Biology and Biotechnology 5: 9-14.

Bidwell, J. R., 2010. Range expansion of Dreissena polymorpha: a review of major dispersal vectors in Europe and North America. In Van der Velde, G., S. Rajagopal \& A. Bij de Vaate (eds), The Zebra Mussels in Europe. Backhuys Publishers, Weikersheim.

Bieler, R., P. M. Mikkelsen, T. M. Collins, E. A. Glover, V. L. Gonzalez, D. L. Graf, E. M. Harper, J. Healy, G. Y. Kawauchi, P. P. Sharma, S. Staubach, E. E. Strong, J. D. Taylor, I. Temkin, J. D. Zardus, S. Clark, A. Guzman, E. McIntyre, P. Sharp \& G. Giribet, 2014. Investigating the Bivalve Tree of Life - an exemplar-based approach combining molecular and novel morphological characters. Invertebrate Systematics 28: 32-115.

Bij de Vaate, A., K. Jazdzewski, H. Ketelaars, S. Gollasch \& G. Van der Velde, 2002. Geographical patters in range extension of Ponto-Caspian macroinvertebrate species in Europe. Canadian Journal of Fisheries and Aquatic Sciences 59: 1159-1174.

Birney, E., M. Clamp \& R. Durbin, 2004. GeneWise and Genomewise. Genome Research 14: 988-995.

Borcherding, J., 1991. The annual reproductive cycle of the freshwater mussel Dreissena polynorpha Pallas in lakes. Oekologia 87: 208-218.

Breton, S., D. T. Stewart \& W. R. Hoeh, 2010. Characterization of a mitochondrial ORF from the gender-associated mtDNAs of Mytilus spp. (Bivalvia: Mytilidae): Identification of the "missing" ATPase 8 gene. Marine Genomics 3: 11-18.

Chatzoglou, E., E. Kyriakou, E. Zouros \& G. C. Rodakis, 2013. The mRNAs of maternally and paternally inherited mtDNAs of the mussel Mytilus galloprovincialis: start/end points and polycistronic transcripts. Gene 520: 156-165.

Conesa, A., S. Gotz, J. M. Garcia-Gomez, J. Terol, M. Talon \& M. Robles, 2005. Blast2GO: a universal tool for annotation, visualization and analysis in functional genomics research. Bioinformatics 21: 3674-3676.

Doublet, V., R. Raimond, F. Grandjean, A. Lafitte, C. SoutyGrosset \& I. Marcade, 2012. Widespread atypical mitochondrial DNA structure in isopods (Crustacea, Peracarida) related to a constitutive heteroplasmy in terrestrial species. Genome 55: 234-244.

Elderkin, C. L., P. L. Klerks \& E. Theriot, 2001. Shifts in allele and genotype frequencies in zebra mussels, Dreissena polymorpha, along the latitudinal gradient formed by the Mississippi River. Journal of the North American Benthological Society 20: 595-605.

Elderkin, C. L., E. J. Perkins, P. L. Leberg, P. L. Klerks \& R. F. Lance, 2004. Amplified fragment length polymorphism (AFLP) analysis of the genetic structure of the zebra mussel, Dreissena polymorpha, in the Mississippi River. Freshwater Biology 49: 1487-1494. 
Finn, R. D., J. Mistry, J. Tate, P. Coggill, A. Heger, J. E. Pollington, O. L. Gavin, P. Gunasekaran, G. Ceric, K. Forslund, L. Holm, E. L. L. Sonnhammer, S. R. Eddy \& A. Bateman, 2010. The Pfam protein families database. Nucleic Acids Research 38: D211-D222.

Giribet, G. \& W. C. Wheeler, 2002. On bivalve phylogeny: a high-level analysis of the Bivalvia (Mollusca) based on combined morphology and DNA sequence data. Invertebrate Biology 121: 271-324.

Giribet, G., A. Okusu, A. R. Lindgren, S. W. Huff, M. Schrödl \& M. K. Nishiguchi, 2006. Evidence for a clade composed of molluscs with serially repeated structures: monoplacophorans are related to chitons. Proceedings of the National Academy of Sciences 103: 7723-7728.

González, V. L., S. C. S. Andrade, R. Bieler, T. M. Collins, C. W. Dunn, P. M. Mikkelsen, J. D. Taylor \& G. Giribet, 2014. Data from: a phylogenetic backbone for Bivalvia: an RNA-seq approach. Dryad Digital Repository. doi:10. 5061/dryad.v31ms.

González, V. L., S. C. S. Andrade, R. Bieler, T. M. Collins, C. W. Dunn, P. M. Mikkelsen, J. D. Taylor \& G. Giribet, 2015. A phylogenetic backbone for Bivalvia: an RNA-seq approach. Proceedings of the Royal Society B-Biological Sciences 282: UNSP 20142332.

Griffiths-Jones, S., 2003. Rfam: an RNA family database. Nucleic Acids Research 31: 439-441.

Hebert, P. D. N., B. W. Muncaster \& G. L. Mackie, 1989. Ecological and genetic studies on Dreissena polymorpha (Pallas): a new mollusc in the Great Lakes. Canadian Journal of Fisheries and Aquatic Sciences 46: 1491-1587.

Johnson, L. E. \& J. T. Carlton, 1996. Post-establishment spread in largescale invasions: dispersal mechanisms of the zebra mussel Dreissena polymorpha. Ecology 77: 1686-1690.

Karatayev, A. Y., L. E. Burlakova \& D. K. Padilla, 1997. The effects of Dreissena polymorpha (Pallas) invasion on aquatic communities in Eastern Europe. Journal of Shellfish Research 16: 187-203.

Karatayev, A. Y., D. Boltovskoy, D. K. Padilla \& L. E. Burlakova, 2007. The invasive bivalves Dreissena polymorpha and Limnoperna fortunei: parallels, contrasts, potential spread and invasion impact. Journal of Shellfish Research 26: 205-213.

Kołodziejczyk, A., A. M. Łabęcka \& A. Stańczykowska, 2011. Invasion of Corbicula and Dreissena - unexplained problems. In Głowaciński, Z. (ed.), Allien Species in the Fauna of Poland II Key Issues and Summary Conclusions. Instytut Ochrony Przyrody PAN, Kraków: 551-563.

Laslett, D. \& B. Canbäck, 2008. ARWEN: a program to detect tRNA genes in metazoan mitochondrial nucleotide sequences. Bioinformatics 24: 172-175.

Le, S. Q. \& O. Gascuel, 2008. An improved general amino acid replacement matrix. Molecular Biology and Evolution 25: 1307-1320.

Lewandowski, K., 1991. The occurrence of Dreissena polymorpha (Pall.) in some mesotrophic lakes of the Masurian Lakeland (Poland). Ekologia Polska 39: 273-286.

Lewis, K. M., J. L. Feder \& G. A. Lamberti, 2000. Population genetics of the zebra mussel, Dreissena polymorpha (Pallas): local allozyme differentiation within midwestern lakes and streams. Canadian Journal of Fisheries and Aquatic Sciences 57: 637-643.
Marescaux, J. \& K. Van Doninck, 2013. Using DNA barcoding to differentiate invasive Dreissena species (Mollusca, Bivalvia). Zookeys 365: 235-244.

Marsden, J. E., A. P. Spidle \& B. May, 1995. Genetics of zebra mussel populations throughout the Great Lakes and Europe. Canadian Journal of Fisheries and Aquatic Sciences 52: 836-847.

Marsden, J. E., A. P. Spidle \& B. May, 1996. Review of genetic studies of Dreissena spp. American Zoologist 36: 259-270.

May, B. \& J. E. Marsden, 1992. Genetic identification and implications of another invasive species of dreissenid mussel in the Great Lakes. Canadian Journal of Fisheries and Aquatic Sciences 49: 1501-1506.

Müller, J., D. Hidde \& A. Seitz, 2002. Canal construction destroys the barrier between major European invasion lineages of the zebra mussel. Proceedings of the Royal Society of London. Series B, Biological Sciences 269: 1139-1142.

Nalepa, T. F. \& D. W. Schlosser (eds), 1993. Zebra mussels: Biology, impact, and control. Lewis Publishers, Boca Raton, FL.

Nowak, E., 1974. Animals in expansion. WP, Warszawa. (in Polish).

Passamonti, M. \& V. Scali, 2001. Gender-associated mitochondrial DNA heteroplasmy in the venerid clam Tapes philippinarum (Mollusca Bivalvia). Current Genetics 39: 117-124.

Peñarrubia, L., N. Sanz, C. Pla, O. Vidal \& J. Viñas, 2015. Using massive parallel sequencing for the development, validation, and application of population genetics markers in the invasive bivalve zebra mussel (Dreissena polymorpha). PloS ONE 10: e0120732.

Plazzi, F., A. Ribani \& M. Passamonti, 2013. The complete mitochondrial genome of Solemya velum (Mollusca: Bivalvia) and its relationships with Conchifera. BMC Genomics 14: 1.

Roberts, L., 1990. Zebra mussel invasion threatens U.S. waters. Science 249: 1370-1372.

Sańko, T. J. \& A. Burzyński, 2014. Co-expressed mitochondrial genomes: recently masculinized, recombinant mitochondrial genome is co-expressed with the female - transmitted mtDNA genome in a male Mytilus trossulus mussel from the Baltic Sea. BMC Genetics 15: 28.

Schlosser, D. W. \& C. Schmuckal, 2012. Bibliography of Dreissena polymorpha (zebra mussels) and Dreissena rostriformis bugensis (quaga mussels): 1989 to 2011. Journal of Shellfish Research 31: 1205-1263.

Simão, F. A., R. M. Waterhouse, P. Ioannidis, E. V. Kriventseva \& E. M. Zdobnov, 2015. BUSCO: assessing genome assembly and annotation completeness with single-copy orthologs. Bioinformatics 31: 3210-3212.

Skibinski, D. O. F., C. Gallagher \& C. M. Beynon, 1994. Mitochondrial DNA inheritance. Nature 368: 817-818.

Sleight, V. A., M. A. S. Thorne, L. S. Peck, J. Arivalagan, S. Berland, A. Marie \& M. S. Clark, 2016. Characterisation of the mantle transcriptome and biomineralisation genes in the blunt-gaper clam, Mya truncata. Marine Genomics 27: 47-55.

Śmietanka, B., A. Burzyński \& R. Wenne, 2010. Comparative genomics of marine mussels (Mytilus spp.) gender associated mtDNA: rapidly evolving atp8. Journal of Molecular Evolution 71: 385-400. 
Smith, D. R., 2013. RNA-Seq data: a goldmine for organelle research. Briefings in Functional Genomics 12: 454-456.

Smith-Unna, R., C. Boursnell, R. Patro, J. Hibberd \& S. Kelly, 2016. TransRate: reference free quality assessment of $d e$ novo transcriptome assemblies. Genome Research gr.196469.115.

Soroka, M., 1999. Colonisation of water bodies by the zebra mussel Dreissena polymorpha (Pallas) in the light of genetic studies. Folia Malacologica 7: 245-255.

Soroka, M., 2002. Genetic structure of an invasive bivalve Dreissena polymorpha (Pallas) from Poland - I. Geographical and intra-population variation. Folia Malacologica 10: 175-213.

Soroka, M., 2003. Genetic structure of an invasive bivalve Dreissena polymorpha (Pallas) from Poland - II. Ecological variation. Folia Malacologica 11: 43-55.

Soroka, M., 2010. Genetic differentiation of Dreissena polymorpha from East European countries. In Van der Velde, G., S. Rajagopal \& A. Bij de Vaate (eds), The Zebra Mussels in Europe. Backhuys Publishers, Weikersheim.

Sousa, R., A. Novais, R. Costa \& D. L. Strayer, 2014. Invasive bivalves in fresh waters: impacts from individuals to ecosystems and possible control strategies. Hydrobiologia 735: 233-251.

Spidle, A. P., J. E. Marsden \& B. May, 1994. Identification of the Great Lakes quagga mussel as Dreissena bugensis from the Dnieper River, Ukraine, on the basis of allozyme variation. Canadian Journal of Fisheries and Aquatic Sciences 51: 1485-1489.

Stamatakis, A., 2006. RAxML-VI-HPC: maximum likelihoodbased phylogenetic analyses with thousands of taxa and mixed models. Bioinformatics 22: 2688-2690.

Stamatakis, A., P. Hoover \& J. Rougemont, 2008. A Rapid Bootstrap Algorithm for the RAxML Web Servers. Systematic Biology 57: 758-771.

Stańczykowska, A., 1977. Ecology of Dreissena polymorpha (Pall.) (Bivalvia) in lakes. Polish Archives of Hydrobiology 24: 461-530.
Stańczykowska, A., K. Lewandowski \& M. Czarnoleski, 2010. Distribution and densities of Dreissena polymorpha in Poland - past and present. In Van der Velde, G., S. Rajagopal \& A. Bij de Vaate (eds), The Zebra Mussels in Europe. Backhuys Publishers, Weikersheim.

Stepien, C. A., C. D. Taylor \& A. K. Dabrowska, 2002. Genetic variability and phylogeographical patterns of a nonindigenous species invasion: a comparison of exotic vs. native zebra and quagga mussel populations. Journal of Evolutionary Biology 15: 314-328.

Tarnowska, K., C. Daguin-Thiebaut, S. Pain-Devin \& F. Viard, 2013. Nuclear and mitochondrial genetic variability of an old invader, Dreissena polymorpha (Bivalvia), in French river basins. Biological Invasions 15: 2547-2561.

Therriault, T. W., M. F. Docker, M. I. Orlova, D. D. Heath \& H. J. MacIsaac, 2004. Molecular resolution of the family Dreissenidae (Mollusca: Bivalvia) with emphasis on Ponto-Caspian species, including first report of Mytilopsis leucophaeata in the Black Sea basin. Molecular Phylogenetics and Evolution 30: 479-489.

Van der Velde, G., S. Rajagopal \& A. Bij de Vaate (eds), 2010. The Zebra Mussels in Europe. Backhuys Publishers, Weikersheim.

Vendrami, D. L. J., A. Shah, L. Telesca \& J. I. Hoffman, 2016. Mining the transcriptomes of four commercially important shellfish species for single nucleotide polymorphisms within biomineralization genes. Marine Genomics 27: 17-23.

Wheeler, T. J. \& S. R. Eddy, 2013. nhmmer: DNA homology search with profile HMMs. Bioinformatics 29: 2487-2489.

Yarra, T., K. Gharbi, M. Blaxter, L. S. Peck \& M. S. Clark, 2016. Characterization of the mantle transcriptome in bivalves: pecten maximus, Mytilus edulis and Crassostrea gigas. Marine Genomics 27: 9-15.

Zouros, E., A. O. Ball, C. Saavedra \& K. R. Freeman, 1994. Mitochondrial DNA inheritance. Nature 368: 818. 